\title{
References
}

1. Raoult D, Brouqui P, Roux V. A new spotted-fever-group rickettsiosis. Lancet. 1996;348:412. http://dx.doi.org/10.1016/ S0140-6736(05)65037-4

2. Fournier PE, Gouriet F, Brouqui P, Lucht F, Raoult D. Lymphangitis-associated rickettsiosis, a new rickettsiosis caused by Rickettsia sibirica mongolotimonae: seven new cases and review of the literature. Clin Infect Dis. 2005;40:1435-44. http://dx.doi.org/10.1086/429625

3. Apanaskevich DA, Horak IG. The genus Hyalomma Koch, 1844: $\mathrm{V}$. Re-evaluation of the taxonomic rank of taxa comprising the H. (Euhyalomma) marginatum Koch complex of species (Acari: Ixodidae) with redescription of all parasitic stages and notes on biology. International Journal of Acarology. 2008;34:13-42. http://dx.doi.org/10.1080/01647950808683704

4. Orkun Ö, Karaer Z, Çakmak A, Nalbantoğlu S. Spotted fever group rickettsiae in ticks in Turkey. Ticks Tick Borne Dis. 2014;5:213-8. http://dx.doi.org/10.1016/j.ttbdis.2012.11.018

5. Fournier PE, Roux V, Raoult D. Phylogenetic analysis of spotted fever group rickettsiae by study of the outer surface protein rOmpA. Int J Syst Bacteriol. 1998;48:839-49. http://dx.doi.org/ 10.1099/00207713-48-3-839

6. Parola P, Paddock CD, Socolovschi C, Labruna MB, Mediannikov O, Kernif T, et al. Update on tick-borne rickettsioses around the world: a geographic approach. Clin Microbiol Rev. 2013;26:657-702. http://dx.doi.org/10.1128/CMR.00032-13

7. Keskin A, Bursal1 A. Detection of Rickettsia aeschlimannii and Rickettsia sibirica mongolitimonia in Hyalomma marginatum (Acari: Ixodidae) ticks from Turkey. Acarologia. 2016;56:533-6. http://dx.doi.org/10.1051/acarologia/20164140

8. Angelakis E, Richet H, Raoult D. Rickettsia sibirica mongolitimonae infection, France, 2010-2014. Emerg Infect Dis. 2016;22:880-2. http://dx.doi.org/10.3201/eid2205.141989

9. Kuloglu F, Rolain JM, Akata F, Eroglu C, Celik AD, Parola P. Mediterranean spotted fever in the Trakya region of Turkey. Ticks Tick Borne Dis. 2012;3:298-304. http://dx.doi.org/10.1016/ j.ttbdis.2012.10.030

10. Znazen A, Rolain JM, Hammami A, Jemaa MB, Raoult D. Rickettsia felis infection, Tunisia. Emerg Infect Dis. 2006;12:13840. http://dx.doi.org/10.3201/eid1201.050876

Address for correspondence: Ferit Kuscu, Cukurova University Faculty of Medicine, Department of Infectious Diseases and Clinical Microbiology, 01250, Adana, Turkey; email: feritkuscu@gmail.com

\section{Contaminated Stream Water as Source for Escherichia coli 0157 Illness in Children}

\section{William S. Probert, Glen M. Miller, Katya E. Ledin}

Author affiliation: Napa-Solano-Yolo-Marin County Public Health Laboratory, Fairfield, California, USA

DOI: https://dx.doi.org/10.3201/eid2307.170226
In May 2016, an outbreak of Shiga toxin-producing Escherichia coli 0157 infections occurred among children who had played in a stream flowing through a park. Analysis of $E$. coli isolates from the patients, stream water, and deer and coyote scat showed that feces from deer were the most likely source of contamination.

Tn the United States, recreational water is a relatively uncommon source of Shiga toxin-producing Escherichia coli (STEC) 0157 outbreaks (1). We describe an outbreak of STEC O157 infections among children exposed to a contaminated stream in northern California, USA, and provide laboratory evidence establishing wildlife as the source of water contamination.

In May 2016, four cases of Shiga toxin (Stx) 1- and 2-producing E. coli $\mathrm{O} 157$ infection were reported to a local health department in northern California; investigation revealed a common source of exposure. The case-patients, ranging in age from 1 to 3 years, had played in a stream adjacent to a children's playground within a city park. Exposure of the case-patients to the stream occurred on 3 separate days spanning a 2-week period. Two case-patients are known to have ingested water while playing in the stream. Two case-patients were siblings. All case-patients had diarrhea and abdominal cramps; bloody diarrhea was reported for 3. One case-patient was hospitalized with hemolytic uremic syndrome.

The stream is a second-order waterway located in a northern California community of $\approx 7,500$ residents. At the time of exposures, stream flow was $<30 \mathrm{ft}^{3} / \mathrm{s}$. The land upstream is not used for agricultural activities such as livestock production. The community is serviced by a public sewer system; inspection of sewer lines indicated no breach to the system.

Water samples were collected from the exposure site 7 days after the last case-patient was exposed and weekly thereafter for 17 weeks; samples were tested quantitatively for fecal indicator organisms. Throughout the study period, all water samples exceeded recreational water quality limits for E. coli and enterococci levels (2). Water samples were also cultured for STEC isolation and PCR detection of $s t x_{1}$ and $s t x_{2}$ (3). Stx1- and Stx2-producing E. coli $\mathrm{O} 157$ were isolated from stream water each week for the first 4 weeks. Additionally, an Stx2-producing E. coli non-O157 strain was isolated from the stream in the first week of sampling. Enrichment broth cultures of water samples were also positive by PCR for $s t x 1$ and $s t x 2$ for the first 4 weeks of sampling. Thereafter, both $s t x_{1}$ and $s t x_{2}$, or $s t x_{2}$ only, were intermittently detected in enrichment broth cultures for 9 additional weeks.

In the absence of an obvious source (e.g., upstream agricultural operation or sewer leak), wildlife was considered as a possible contributor to water contamination. 


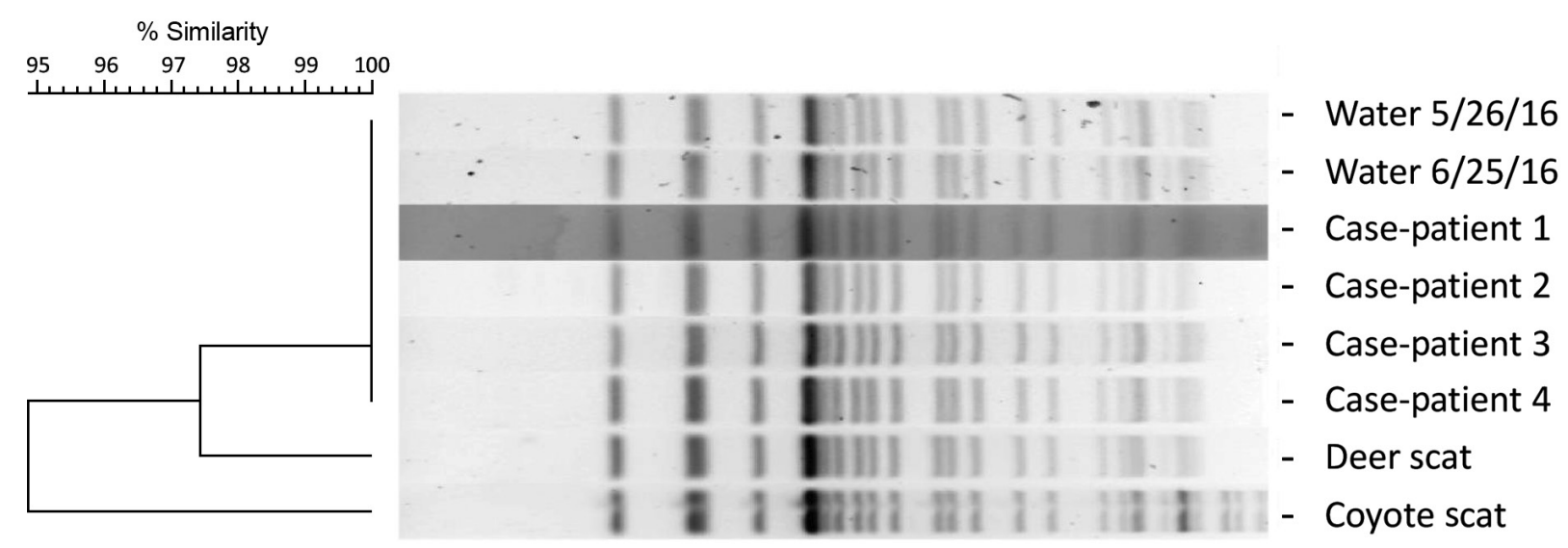

Figure. Pulsed-field gel electrophoresis (PFGE) analysis of Shiga toxin 1- and 2-producing Escherichia coli O157 isolates digested with Xbal. A dendrogram displaying PFGE pattern similarity is shown at left. The PFGE profiles for the case-patients and water isolates were identical and designated as pattern EXH01.0238 by PulseNet (https://www.cdc.gov/pulsenet/). The PFGE patterns for the deer and coyote scat isolates shared $>95 \%$ similarity with pattern EXH01.0238. Dates on water samples indicate date of collection.

Thirteen fresh wildlife scat specimens were collected along the stream for STEC culture and PCR. Of the 13 scat specimens, 8 originated from deer, 2 from raccoon, and 1 each from coyote, turkey, and river otter. Six scat specimens (4 deer, 1 coyote, 1 river otter) were positive for $s t x_{1}$ and $s t x_{2}$ or for $s t x_{2}$ by PCR (online Technical Appendix, https:// wwwnc.cdc.gov/EID/article/23/7/17-0226-Techapp1.pdf). Stx1- and Stx2-producing E. coli $\mathrm{O} 157$ were isolated from deer scat and coyote scat. An Stx2-producing E. coli nonO157 strain was isolated from a deer scat specimen. The animal origin of the coyote and river otter scat specimens were definitively identified by partial DNA sequencing of mitochondrial cytochrome b (4).

To assess strain relatedness, we compared STEC O157 isolates from the case-patients, water, deer scat, and coyote scat by using pulsed-field gel electrophoresis (PFGE) and multilocus variable-number tandem-repeat analysis (MLVA) (5). PFGE patterns for XbaI-digested genomic DNA were highly similar among all isolates; only slight variations were found in the lower-sized bands (Figure). PFGE patterns for genomic DNA samples digested with $B \ln \mathrm{I}$ also demonstrated a high degree of similarity (data not shown). Furthermore, MLVA profiles were identical for the case-patient, water, and deer scat isolates; only the coyote scat isolate differed from the main profile by 2 repeats at a single locus (VNTR_3).

This study provides laboratory evidence linking STEC O157 infections with the ingestion of recreational water that was probably contaminated by wildlife scat. Wild ruminants, including deer and elk, are known carriers of STEC and have been connected to outbreaks of human infections (6-9). We detected STEC in 50\% of deer scat specimens collected from the stream bank. One of these specimens, found 1.5 miles upstream of the exposure site, contained an E. coli $\mathrm{O} 157$ isolate that was highly similar by molecular subtyping to case-patient and water isolates. These findings support the likelihood that feces from deer carrying STEC were the source of water contamination or, at the very least, contributed to the persistence of STEC in the water. It is unknown whether the STEC detected in coyote and river otter scat represents carriage or transitory colonization within these animals.

The common risk factor among the case-patients in this STEC O157 outbreak was exposure to a natural stream within a city park. After the outbreak was recognized, signs warning of bacterial contamination were posted along the stream. No further STEC O157 infections attributed to stream water exposure were reported.

\section{Acknowledgments}

We thank Frank Reyes, Keith Snipes, and Nailah Souder for their technical assistance; the County of Marin Health and Human Services and Environmental Health Services for information about the epidemiologic and environmental investigation; and the Microbial Diseases Laboratory Branch of the California Department of Public Health and the Santa Clara County Public Health Laboratory for the molecular subtyping data.

Dr. Probert is the assistant director for the Napa-SolanoYolo-Marin County Public Health Laboratory. His research interests focus on the development of molecular diagnostic tools for the detection of infectious agents.

\section{References}

1. Heiman KE, Mody RK, Johnson SD, Griffin PM, Gould LH, Escherichia coli O157 outbreaks in the United States, 2003-2012. Emerg Infect Dis. 2015;21:1293-301. http://dx.doi.org/10.3201/ eid2108.141364 
2. United States Environmental Protection Agency. 2012. Recreational water quality criteria. Office of Water 820-F-12-058 [cited 2017 Apr 13]. https://www.epa.gov/sites/production/ files/2015-10/documents/rwqc2012.pdf

3. Probert WS, McQuaid C, Schrader K. Isolation and identification of an Enterobacter cloacae strain producing a novel subtype of Shiga toxin type 1. J Clin Microbiol. 2014;52:2346-51. http://dx.doi.org/10.1128/JCM.00338-14

4. Parson W, Pegoraro K, Niederstätter H, Föger M, Steinlechner M. Species identification by means of the cytochrome $\mathrm{b}$ gene. Int J Legal Med. 2000;114:23-8. http://dx.doi.org/10.1007/ s004140000134

5. Hyytia-Trees E, Lafon P, Vauterin P, Ribot EM. Multilaboratory validation study of standardized multiple-locus variable-number tandem repeat analysis protocol for Shiga toxin-producing Escherichia coli O157: a novel approach to normalize fragment size data between capillary electrophoresis platforms. Foodborne Pathog Dis. 2010;7:129-36. http://dx.doi.org/10.1089/ fpd.2009.0371

6. Fischer JR, Zhao T, Doyle MP, Goldberg MR, Brown CA, Sewell CT, et al. Experimental and field studies of Escherichia coli O157:H7 in white-tailed deer. Appl Environ Microbiol. 2001;67:1218-24. http://dx.doi.org/10.1128/AEM.67.3.12181224.2001

7. Keene WE, Sazie E, Kok J, Rice DH, Hancock DD, Balan VK, et al. An outbreak of Escherichia coli O157:H7 infections traced to jerky made from deer meat. JAMA. 1997;277:1229-31. http://dx.doi.org/10.1001/jama.1997.03540390059036

8. Rounds JM, Rigdon CE, Muhl LJ, Forstner M, Danzeisen GT, Koziol BS, et al. Non-O157 Shiga toxin-producing Escherichia coli associated with venison. Emerg Infect Dis. 2012;18:279-82. 10.3201/eid1802.110855 http://dx.doi.org/10.3201/eid1802.110855

9. Laidler MR, Tourdjman M, Buser GL, Hostetler T, Repp KK, Leman R, et al. Escherichia coli O157:H7 infections associated with consumption of locally grown strawberries contaminated by deer. Clin Infect Dis. 2013;57:1129-34. http://dx.doi.org/10.1093/cid/cit468

Address for correspondence: William S. Probert, County of Solano, Public Health Laboratory, 2201 Courage Dr, Fairfield, CA 94533, USA; email: will.probert60@gmail.com

\section{Diphtheria in Mayotte, 2007-2015}

\section{Emmanuel Belchior, ${ }^{1}$ Sabine Henry, ${ }^{1}$ Edgar Badell, Louis Collet, Thierry Benoit-Cattin, Anne-Marie de Montera, Nicole Guiso, Olivier Patey, Daniel Levy-Bruhl, Laurent Filleul, Francois Chieze, Sophie Olivier}

Author affiliations: Santé Publique France, Saint-Maurice, France (E. Belchior, D. Levy-Bruhl); Agence Régionale de Santé Océan Indien, Saint-Denis, France (S. Henry, F. Chieze); Institut Pasteur, Paris, France (E. Badell, N. Guiso); Centre Hospitalier de Mayotte,

${ }^{1}$ These authors contributed equally to this article.
Mamoudzou, France (L. Collet, T. Benoit-Cattin, A.-M. de Montera, S. Olivier); Centre Hospitalier Intercommunal, Villeneuve-SaintGeorges, France (O. Patey); Santé Publique France, Saint-Denis de La Réunion, France (L. Filleul)

DOI: https://doi.org/10.3201/eid2307.170262

Epidemiology of diphtheria in the southwestern Indian Ocean is poorly documented. We analyzed 14 cases of infection with toxigenic Corynebacterium diphtheriae reported during 2007-2015 in Mayotte, a French department located in this region. Local control of diphtheria is needed to minimize the risk for importation of the bacterium into diseasefree areas.

$\mathrm{D}$ iphtheria due to toxigenic Corynebacterium diphtheriae occurs sporadically across Europe, mostly in persons who emigrated from disease-endemic countries $(1,2)$. Systemic toxic effects occur in cutaneous diphtheria but less commonly than in pharyngeal or laryngeal diphtheria. C. diphtheriae is a well-recognized cause of chronic, nonhealing skin ulcers in the tropics $(3,4)$. In France, diphtheria has been a reportable disease since 1945. A vaccination program began in the late 1940s; no cases were reported during 1990-2001, and 13 cases were reported, all in visitors or immigrants to France, since 2002. However, the epidemiology of diphtheria in the southwestern Indian Ocean region, where several French departments are located, is poorly documented.

Mayotte, a French department, is an island of the Comoros archipelago (Figure) and an attractive destination for migrants from the area. In 2012, Mayotte had 212,645 inhabitants, at least $40 \%$ foreign born (5). We analyzed all cases of infection with toxigenic $C$. diphtheriae reported in Mayotte since 2007 to evaluate the potential risk for dissemination of diphtheria inside and outside this area.

During 2007-2015, local hospitals reported 14 cases of toxigenic $C$. diphtheriae infection to the local health authorities: 1 case in an infant with severe respiratory symptoms who died from multiple organ failure and 13 cutaneous diphtheria cases in patients who survived. Most of the patients $(11 / 14)$ were male, and the median age was 11 years (range 2 months-39 years). Eight patients had recently (most within 1 month) emigrated from neighboring islands.

Patients' medical history was usually unknown, but vaccination status was available for 12 patients: 7 had received $\geq 3$ doses of diphtheria vaccine according to the vaccination schedule of France ( 6 ) and 5 were unvaccinated (the infant, 2 children, and 2 adults). All cutaneous infections occurred in patients with preexisting wounds. Eleven patients had chronic diphtheria infections (1-36 months) with 